\title{
Extreme bone lengthening by bone transport with a unifocal tibial corticotomy: a case report
}

\author{
Hongjie Wen ${ }^{1}$, Huagang Yang ${ }^{1}$ and Yongqing $\mathrm{Xu}^{2^{*}}$
}

\begin{abstract}
Background: Bone transport is used for the treatment of extensive limb bone defects. The application of ring or unilateral external fixators combined with single or double corticotomy are well documented; however, there are few cases adopting a single corticotomy to repair bone defects $>24 \mathrm{~cm}$.

Case presentation: The present case study describes an 18-year-old male, who was involved in a traffic accident and was diagnosed with open fracture of the right tibia. The patient received emergency surgery in a local hospital and was transferred to The Second People's Hospital of Yunnan for further treatment 3 months later. The patient was diagnosed with fracture nonunion and infection following admission. Complete debridement was performed three times to control the infection. The infection was resolved after 26 days and the $24.5 \mathrm{~cm}$ massive tibia defect remained the biggest challenge. The bone transport technique involving a unilateral external fixator and single corticotomy was employed to treat the bone defect. Docking site union was achieved and bone consolidation was complete 40 months after corticotomy. The external fixator was subsequently removed. The bone healing index was 1.6 months $/ \mathrm{cm}$. The Association for the Study and Application of the Method of Ilizarov criteria (ASAMI) revealed a good functional and bone repair result. Similarly, Knee Society Score (KSS) yielded good result and the The Lower Extremity Functional Scale (LEFS) was 65. A total of 45 months after injury, the patient was able to walk painlessly without ambulatory assistive devices and resumed daily activities successfully. Eighteen months after the bone and soft tissue wound have healed, the SF-36 score was 86, and the LEFS was 70.
\end{abstract}

Conclusion: To the best of the authors' knowledge, the present study described the longest bone defect repair performed using bone transport with single level corticotomy.

Keywords: llizarov technique, Tibial nonunion, Bone defects, Bone transport

\section{Background}

Tibial defects $>5 \mathrm{~cm}$ secondary to high-energy trauma or debridement following nonunion pose a significant challenge in orthopedic surgery [1]. Methods for treating massive bone defects include bone transport, Masquelet technique and bone grafts with or without vascular pedicle. Each method has its advantages and disadvantages [2-6]. The Ilizarov technique is currently the gold standard treatment for large segmental defects as it does not require large amounts of soft tissue and autologous bone grafts. Furthermore, infections are adequately controlled and bone and soft tissue defects may be repaired at the same time [7]. According to current literature, single and double osteotomies have been performed for bone transfers up to 22 and 14.5 $\mathrm{cm}$ in length, respectively [8-10].

The present case study demonstrated the application of unilateral external fixator and single osteotomy for the treatment of infected tibial bone defects caused by severe trauma.

\footnotetext{
* Correspondence: whj20000@163.com

${ }^{2}$ Department of Orthopedic Surgery, 920th Hospital of Joint Logistics

Support Force, 212 Daguan Road, Xi Shan District, Kunming, Yunnan 650031,

People's Republic of China

Full list of author information is available at the end of the article
}

(c) The Author(s). 2019 Open Access This article is distributed under the terms of the Creative Commons Attribution 4.0 International License (http://creativecommons.org/licenses/by/4.0/), which permits unrestricted use, distribution, and reproduction in any medium, provided you give appropriate credit to the original author(s) and the source, provide a link to the Creative Commons license, and indicate if changes were made. The Creative Commons Public Domain Dedication waiver (http://creativecommons.org/publicdomain/zero/1.0/) applies to the data made available in this article, unless otherwise stated. 


\section{Case presentation}

In September 2014, an 18-year-old, non-smoking male was diagnosed with an open fracture of the right tibia, Gustilo's classification grade IIIB [11] following a traffic accident. The patient weighed $65 \mathrm{~kg}$. Emergency debridement was performed at the local hospital following injury (Fig. 1a and b). The fracture and wound had not healed 3 months after injury. Copious pus was drained and the patient was transferred The Second People's Hospital of Yunnan for further treatment.

The patient was admitted to The Second People's Hospital of Yunnan 97 days after the injury. A physical examination of the patient's right calf revealed a soft tissue defect and exposed tibia. A $4 \times 10 \mathrm{~cm}$ incision was observed on the anterior medial side of the upper calf and a $3 \times 12 \mathrm{~cm}$-sized wound was seen on the anterior medial side of the lower leg. Significant foot drop was observed. The patient experienced hypoesthesia on the lateral side of right calf and the dorsal surface of the foot; however, normal sensation was felt on the plantar surface of the foot and the dorsalis pedis artery appeared normal. The range of motion of the knee was $0-80^{\circ}$, and ankle extension and flexion were 10 and $20^{\circ}$, respectively. Level III myodynamia was observed in the pretibial muscle and the triceps surae (Fig. 2).

Following discussion with the patient, a limb salvage protocol was adopted in favor of amputation. The treatment plan consisted of two stages. The first step was to treat the infection by performing repeated debridement, replacing the external fixation, vacuum sealing drainage (VSD) and local and systemic application of antibiotics. In the second stage, the bone transport technique was used to repair the bone defect, and rehabilitation exercise was performed to restore the function of the affected limb as much as possible. The patient was informed about the treatment plan and the associated risks. A series of examinations were performed to assess the tibial infection. An X-ray revealed necrosis and hyperplasia in the middle of tibia (Fig. 3). Single-photon emission computed tomography showed radionucleotide accumulation in the midtibial region and computed tomography angiography confirmed that the anterior and posterior tibial arteries were normal. Laboratory investigations were as follows: i) C-reactive protein, $21.6 \mathrm{mg} / \mathrm{l}$ : ii) erythrocyte sedimentation rate, 35 $\mathrm{mm} / \mathrm{h}$; iii) white blood cell count, $16.47 \times 10^{9} / \mathrm{l}$; and iv) Neutrophil percentage, 84.51[50-70]. The final diagnosis was an infected right tibial nonunion with a soft tissue defect.

Debridement to completely remove the infected and devitalized bone, inflammatory and scar tissue was performed on the second day after admission (Fig. 4). The debrided bone was replaced with a three-segment monolateral external fixator (Third Medical Instrument

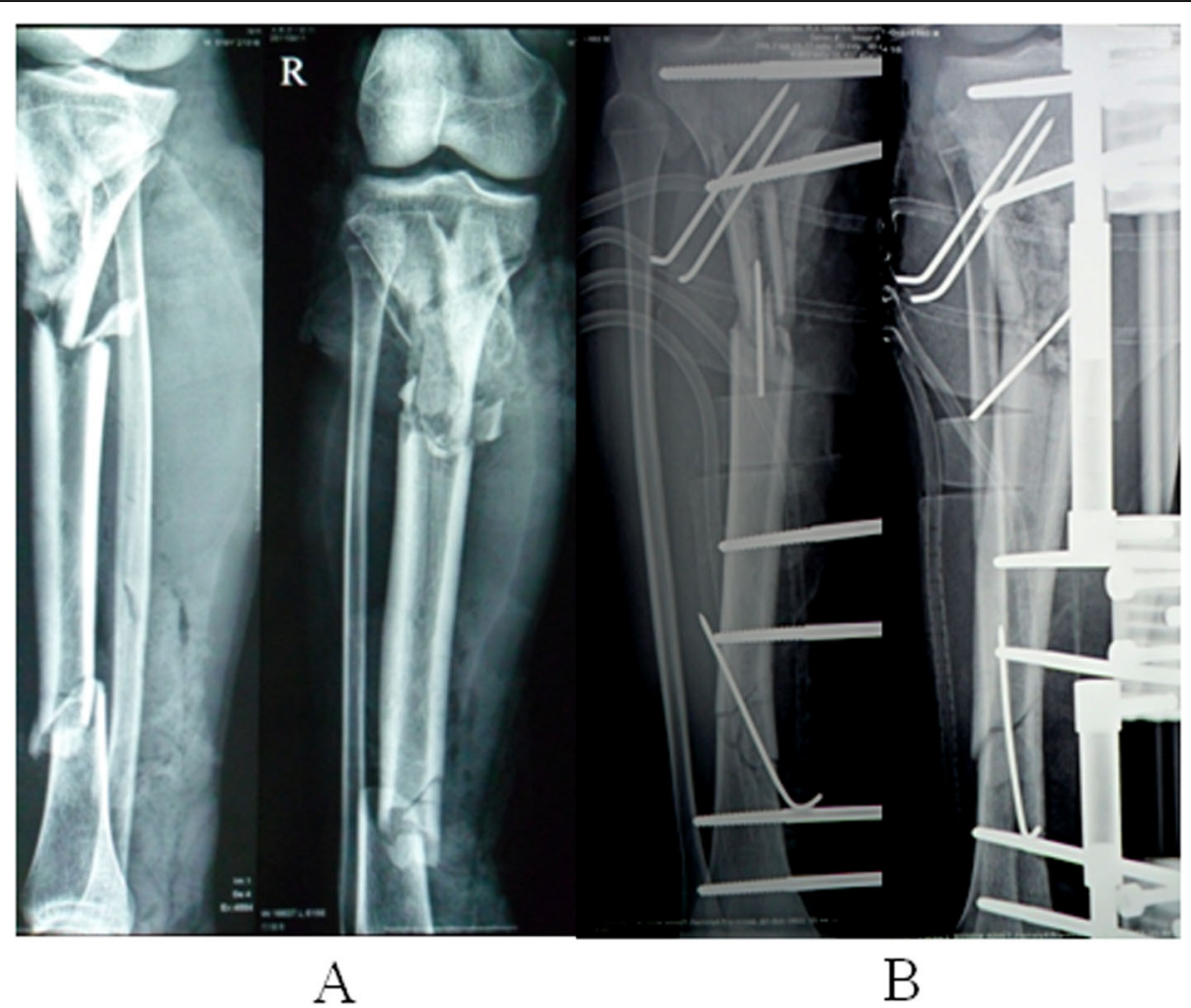

Fig. 1 X-ray (a) at the time of injury and (b) following emergency debridement in the local hospital 

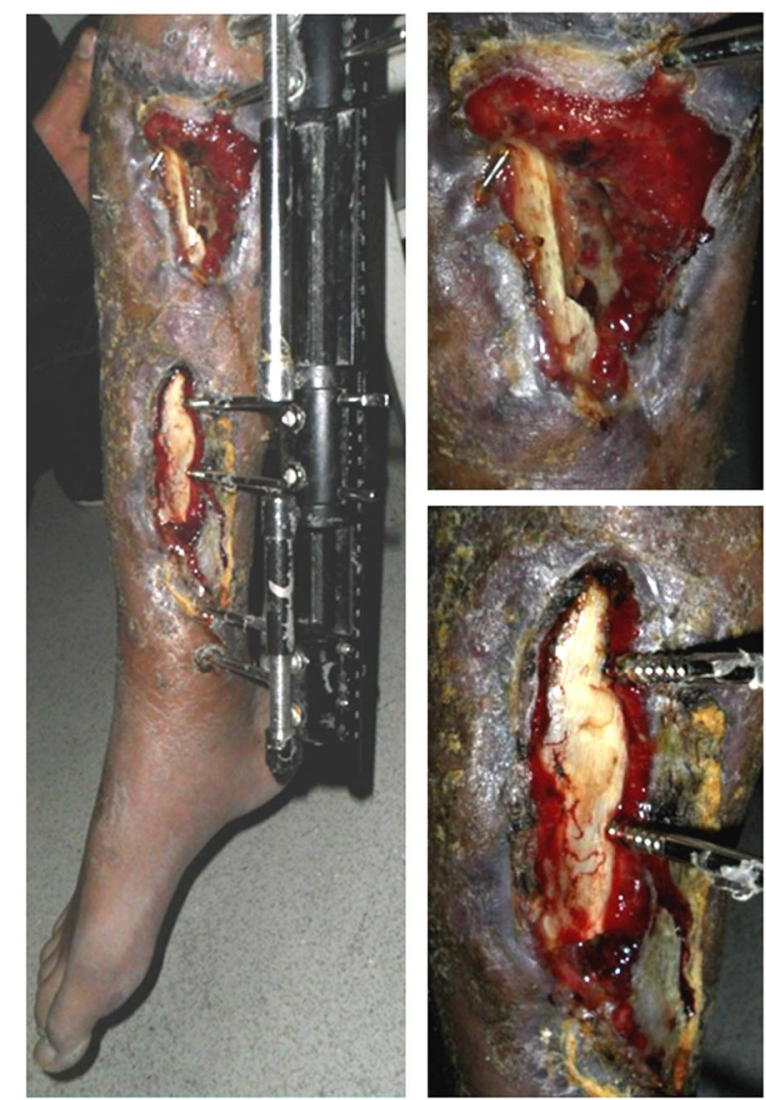

Fig. 2 A $4 \times 10 \mathrm{~cm}$ incision was observed on the anterior medial side of the upper calf and a $3 \times 12 \mathrm{~cm}$ wound was seen on the anterior medial side of the lower leg. Significant foot drop was observed

Company; Fig. 5) followed by the implantation of vancomycin-impregnated cement beads (4 g vancomycin and $80 \mathrm{~g}$ cement) in the bone defects (Fig. 6). The wound was partially closed and the dressing was changed regularly following surgery. The second debridement was performed 5 days after the initial procedure and involved the removal of inflammatory tissue and the antibiotic beads. VSD was used to cover the wound and to promote the growth of granulation tissue while simultaneously draining pus. The third debridement was performed 5 days after the second procedure, and involved the removal of the VSD. The wound appeared clean and was subsequently sutured. At this point, the bone defect measured $25 \mathrm{~cm}$ in length. Antibiotic sensitivity testing was performed following each of the three debridement procedures and Methicillin-resistant Staphylococcus aureus, Escherichia coli, Klebsiella pneumoniae and Enterococcus faecalis were identified. Vancomycin and meropenem through the veins were used to treat the infection. Wound healing and infection control marked the end of the first stage of the treatment plan.

The repair of the massive bone defect posed the biggest challenge during the second stage of the treatment

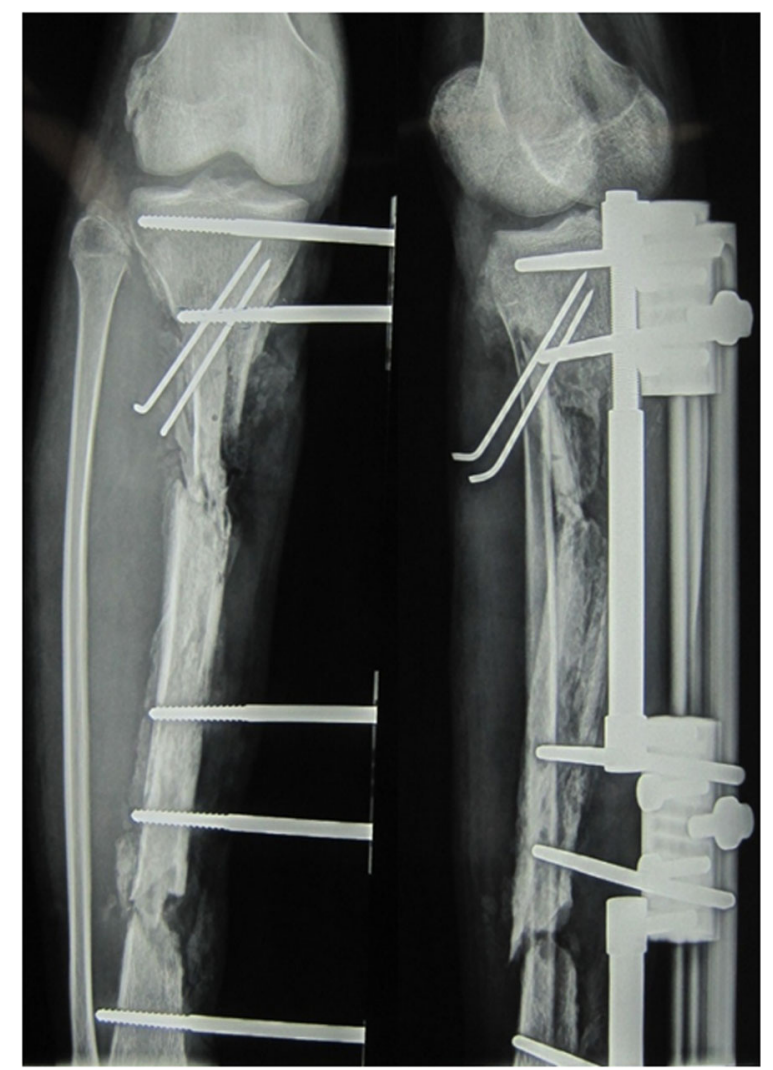

Fig. 3 Preoperative $X$-ray on the day of admission at The Second People's Hospital of Yunnan demonstrating the necrotic bone

plan. As bone transfer technology has a number of advantages, this technique was applied. Wound healing and infection control were assessed through relevant indicators and when satisfactory, a single osteotomy was performed $2 \mathrm{~cm}$ away from the ankle joint surface (Fig. 7). Bone transport was initiated 1 week later at a rate of $1 \mathrm{~mm}$ per day $(0.25 \mathrm{~mm}$ four times a day). The quality of the newly formed bone was assessed 2, 4 and 6 months after osteotomy using X-rays (Fig. 8), which revealed satisfactory osteogenesis was occurring. A total of 15 months after osteotomy, the distracted bone had reached docking site, which resulted in skin invagination and axis deviation (Fig. 9). The embedded soft tissue was removed and the axis was adjusted. To promote docking site union, the external fixation was loosened and increasing load across the site of osteogenesis were gradually added. The total length of transport was $24.5 \mathrm{~cm}$. After 40 months, union was achieved and the consolidation of the newly formed bone was complete (Fig. 10). The patient exhibited the following range of motion: i) Knee extension, $0^{\circ}$; ii) knee flexion, $110^{\circ}$; iii) ankle extension, $10^{\circ}$; and iv) knee flexion, $10^{\circ}$ (Fig. 11). A knee valgus deformity angle of $4^{\circ}$ and a $10 \mathrm{~mm}$ shortening of the tibia were observed. The bone healing index was 1.6 


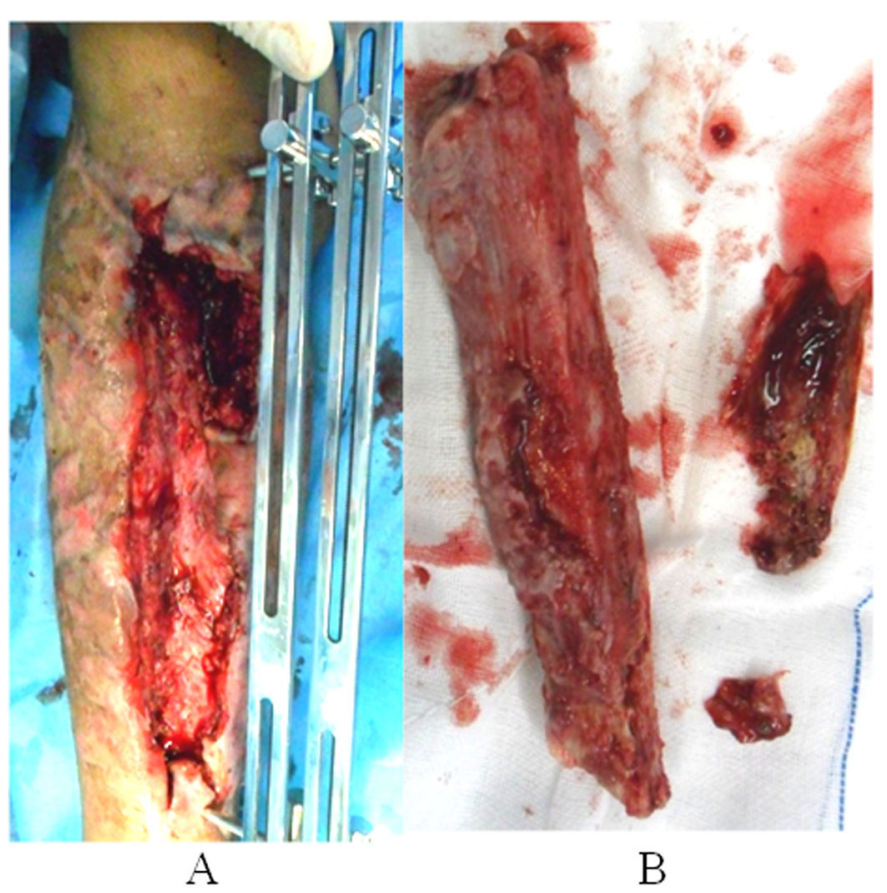

Fig. 4 The first debridement procedure. a Significant purulent necrotic tissue was attached to the necrotic bone. $\mathbf{b}$ No bleeding was observed in the bone cortex

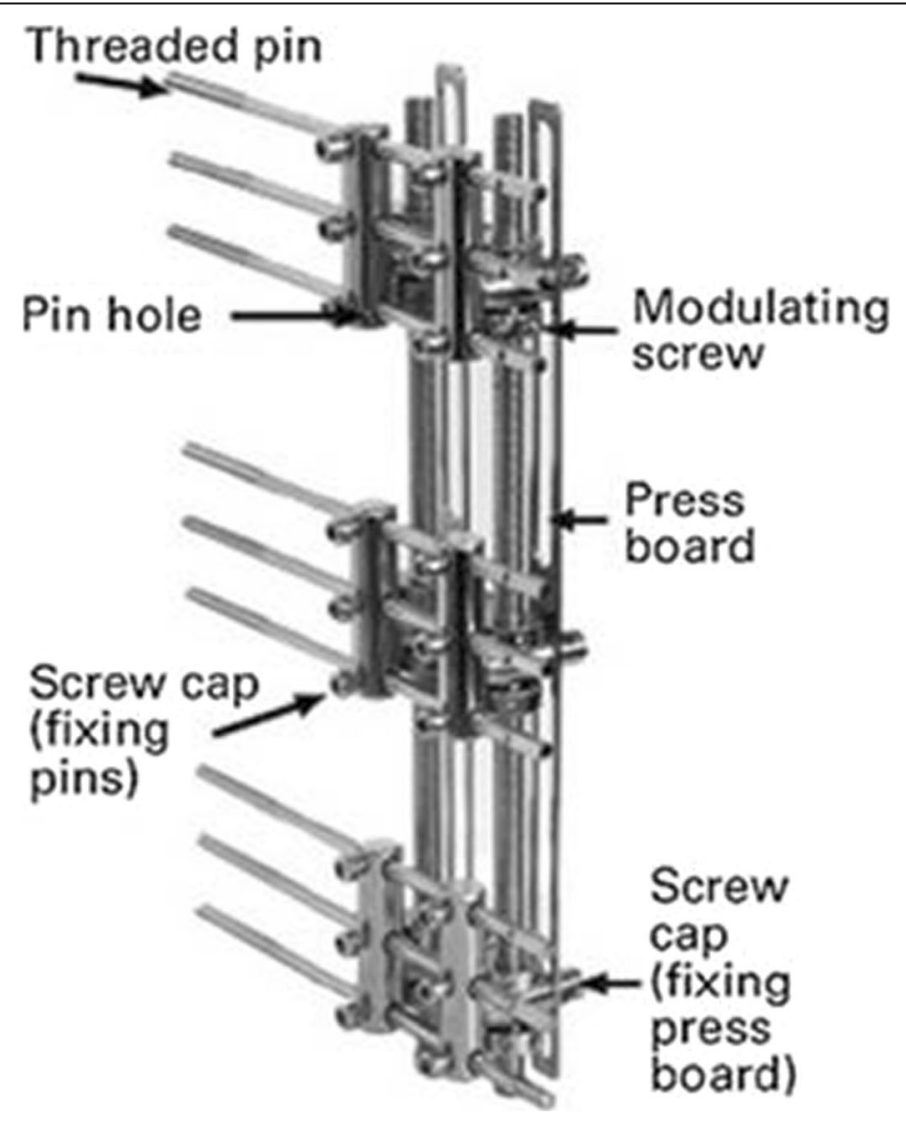

Fig. 5 Three-segment monolateral external fixator (Third Medical Instrument Company, Wujin, China) 


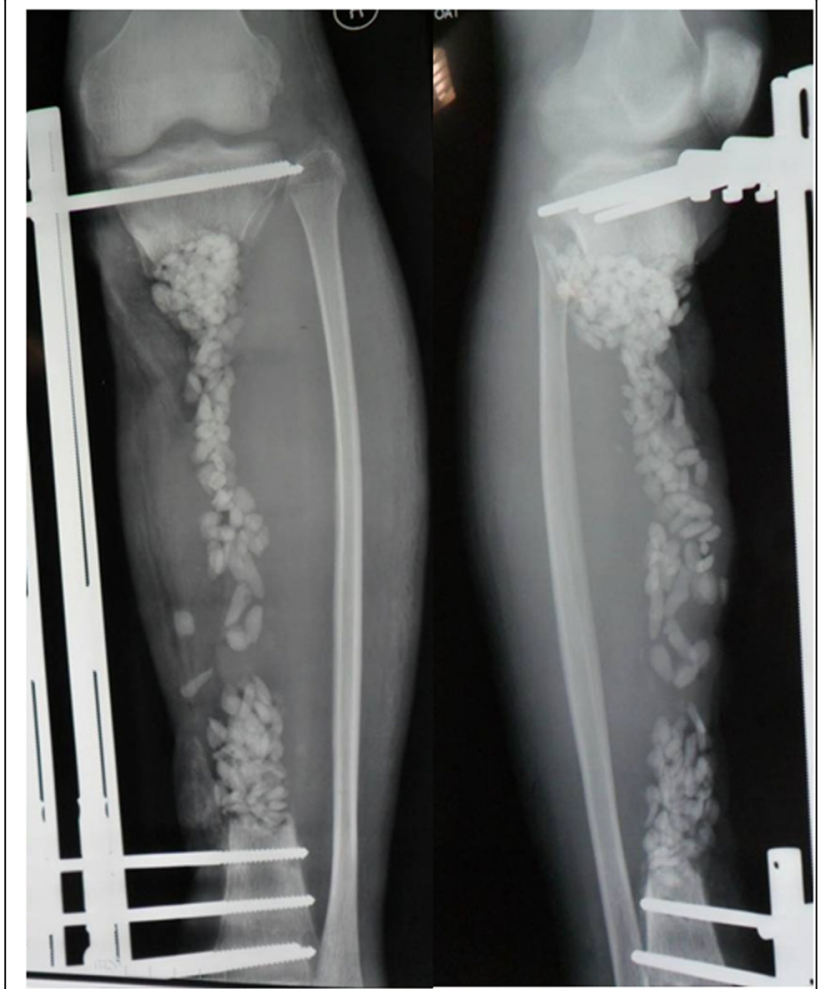

Fig. 6 X-ray showing the vancomycin-impregnated cement beads that were placed during the first debridement

months $/ \mathrm{cm}$. When the bone and soft tissue wound have healed, the patient was able to walk painlessly without ambulatory assistive devices and resumed daily activities successfully. The ASAMI [12] was used to assess the limb function and bone healing, and revealed a good functional and bone repair result. Similarly, the KSS of functional outcome yielded good result [13] and the LEFS [14] was 65.

Eighteen months after the bone and soft tissue wound have healed, we performed a follow-up evaluation with Short Form-36 (SF-36) score [15] and LEFS (Additional files 1, 2 and 3). The SF-36 score was 86 , and the LEFS was 70 . The overall treatment progress is briefly presented in Table 1.

\section{Discussion and conclusions}

The clinical treatment of massive limb bone defects remains challenging $[2,7,16]$ as such injuries require a long treatment period, repeated surgeries and may result in suboptimal outcomes. Furthermore, treatment is associated with high cost and is often accompanied by a high amputation rate [16]. There are currently three main methods to tackle massive bone defects: i) Bone transport using the Ilizarov technique; ii) the Masquelet technique; and iii) bone graft with or without vascular pedicle [16]. The Masquelet technique is controversial,

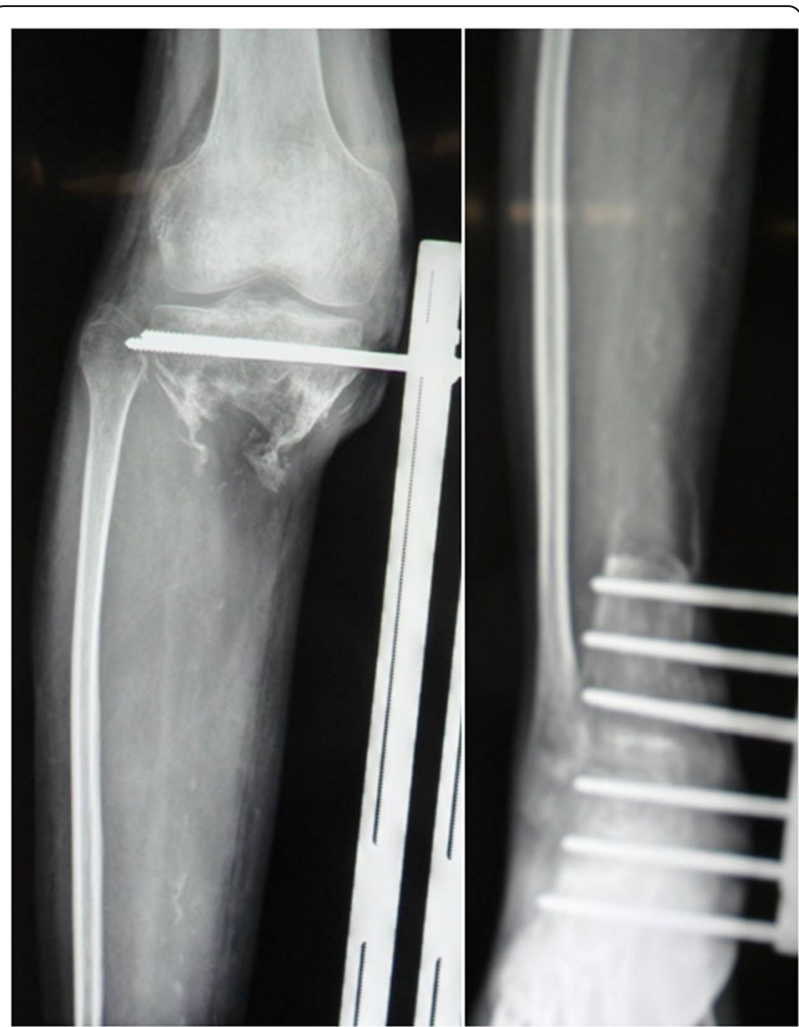

Fig. $7 \mathrm{~A}$ single osteotomy on the tibia $2 \mathrm{~cm}$ away from ankle joint surface was performed

as it requires an autologous bone graft that is difficult to obtain and is associated with recurrent fractures [9]. Furthermore, microsurgical techniques are required. Therefore, the bone transport technique was used to treat bone defects in the present case.

In the present case, the infected bone did not connect due to an open fracture. Following three debridement procedures, the bone defect was $24.5 \mathrm{~cm}$. A large middle bone segment was removed as preoperative imaging examination indicated that this segment was infected and necrotic. Furthermore, no bleeding was occurred in the bone cortex and a large amount of pus was observed in the medullary cavity. The docking site union and consolidation of newly formed bone lasted 25 months. Previous studies revealed that early freshening of the docking site and autologous bone grafting may significantly promote bone union [3, 7, 17-19]. However, in the present case, union was achieved by loosening the external fixation and by the gradual addition of increasing load across the site of osteogenesis.

A bone graft was not performed in the present case for the following reasons: i) The condition of the soft tissue at the docking site was in poor condition and not suitable for bone graft; ii) the docking site was located in the epiphysis region of the tibia, which is served by a rich blood that promotes healing; and iii) the ends of the docking site were wide and union was 


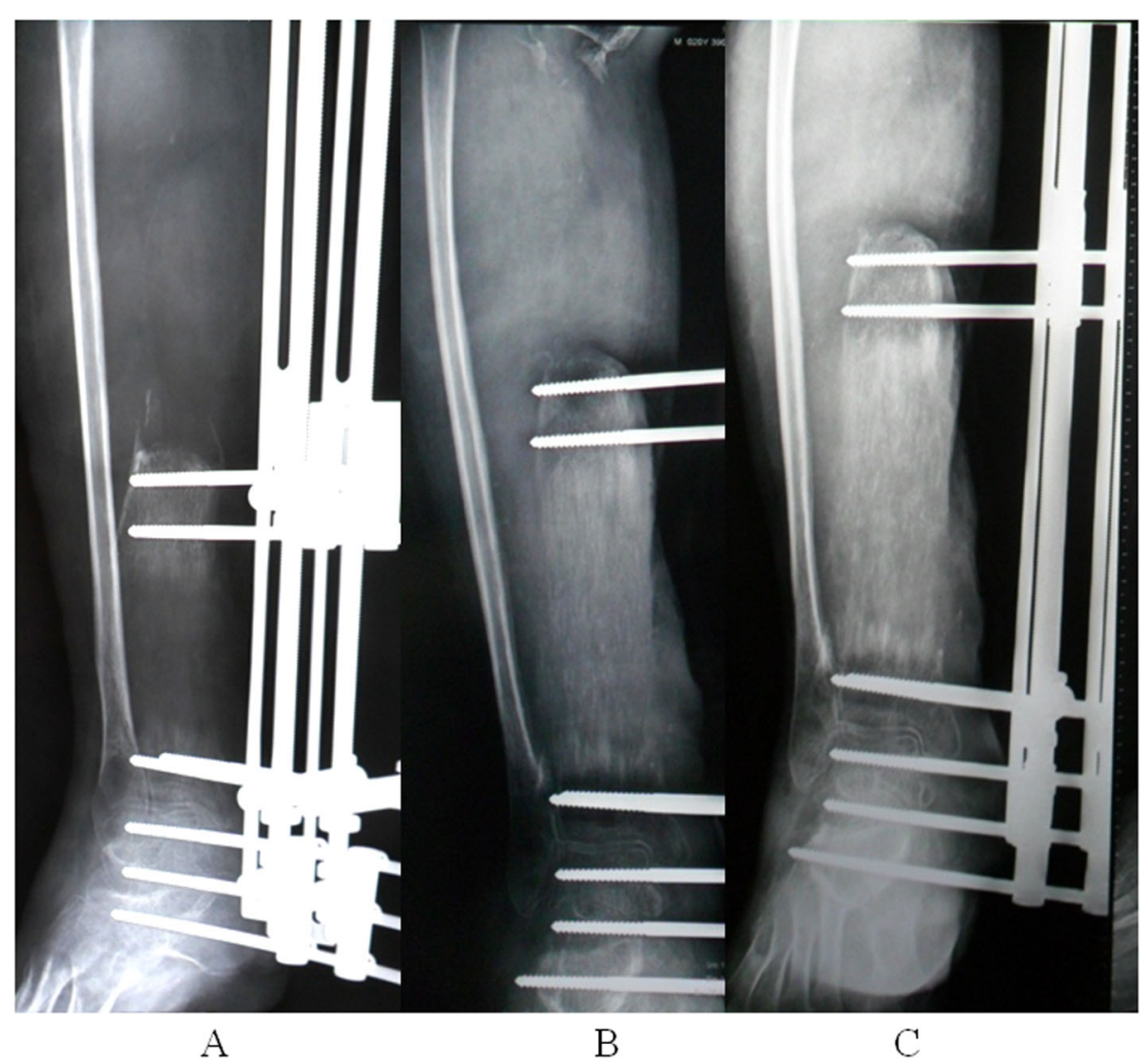

Fig. 8 X-ray performed (a) 2, (b) 4 and (c) 6 months after corticotomy demonstrating bone regeneration

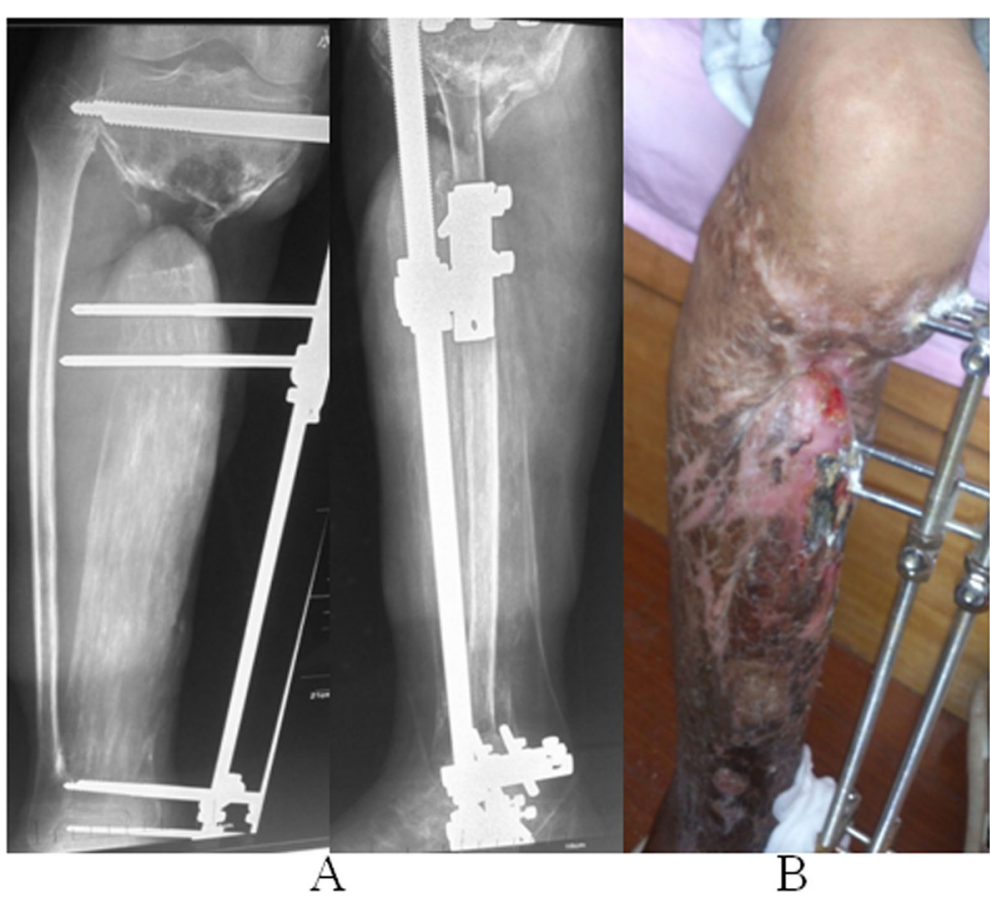

Fig. 9 a Axis deviation and $\mathbf{b}$ soft tissue embedding 15 months after corticotomy 


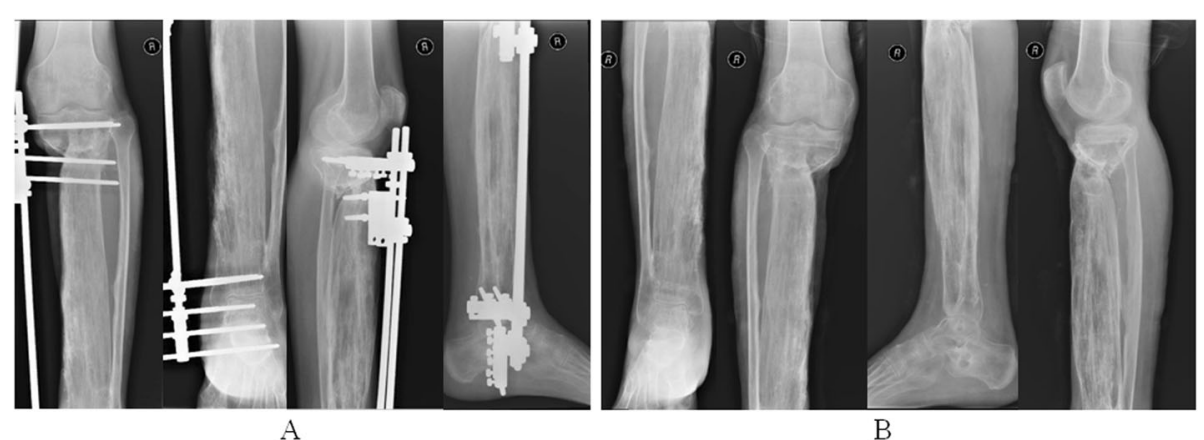

Fig. 10 X-ray performed (a) 40 months after corticotomy and (b) following the removal of the external fixator after complete union at the docking site and bone consolidation

likely to be obtained through compression according to the authors' previous experience. However, the time taken for union to occur may have been shortened if an autologous bone graft was performed. Previous studies revealed that that the Ilizarov technique combined with an intramedullary nail or plate may shorten the treatment period and increase patient comfort [1, 3, 20-23]. However, due to high treatment costs and the potential for infection, the internal fixation device was not changed in the patient.

Previous studies revealed that time taken for union to occur may be significantly shortened by double-site osteotomy, which is safe and effective [7, 24]. However, in the present case, the size of the defect shortened the proximal tibia and a double-site osteotomy was not possible. To the best of the authors' knowledge, the present case report documented the longest bone defect repair performed by single-site corticotomy with bone transport.

16.389ptProblems of axis deviation and soft tissue embedding were encountered during the course of treatment. The axis deviation was corrected by adjusting the external fixation. Surgery was performed to remove the excess soft tissue at the docking site. The complete debridement as well as the removal of the infected and necrotic bone segments in the early stage of treatment were key factors that led to the successful outcome in the present case.

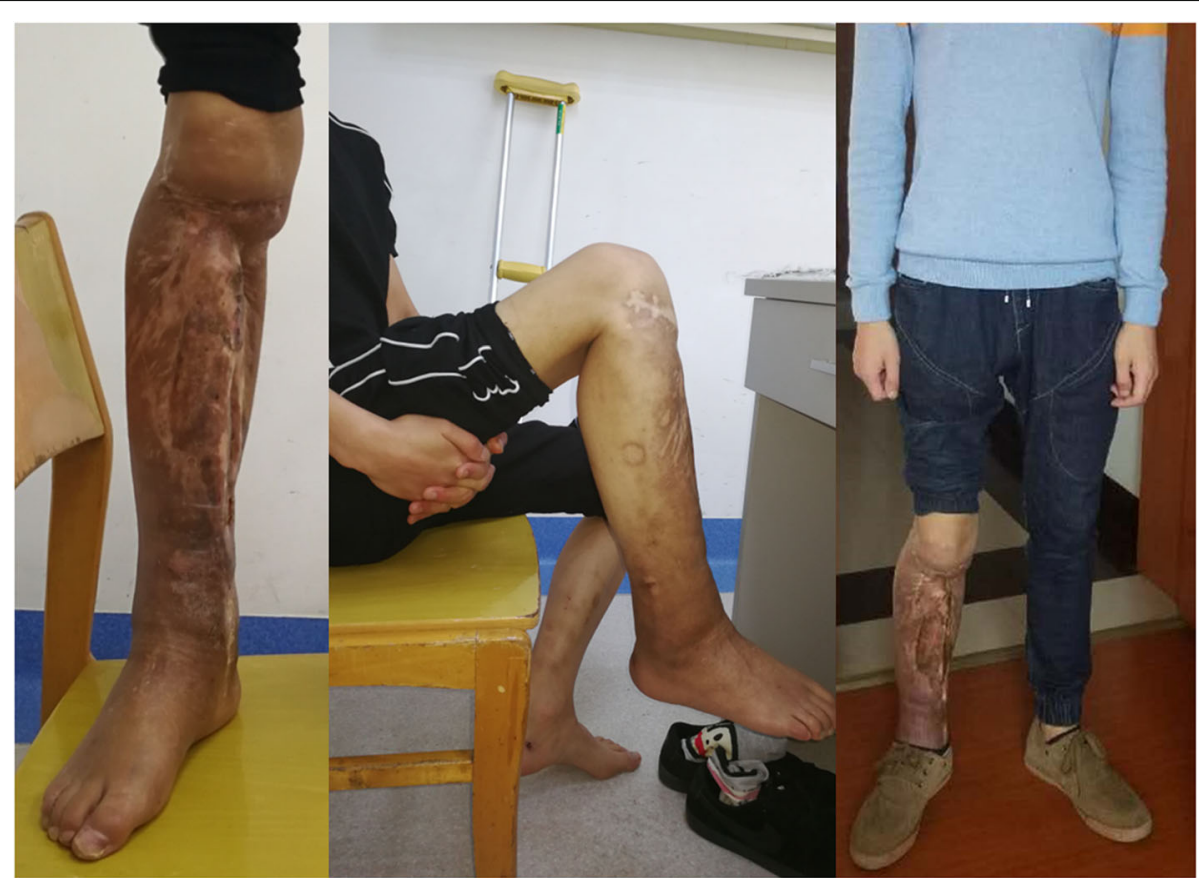

Fig. 11 Follow-up after 4 years. Range of motion at the knee was $0-110^{\circ}$ and $10^{\circ}$ of extension to $10^{\circ}$ of flexion at the ankle 
Table 1 Time line of events from the first debridement performed in our department until removal of the external fixator

\begin{tabular}{|c|c|}
\hline $\begin{array}{l}\text { Day after } \\
\text { admission }\end{array}$ & Event \\
\hline Day 2 & $\begin{array}{l}\text { First debridement (removing the massive bone defect } \\
\text { and changing the external fixator). }\end{array}$ \\
\hline Day 7 & Second debridement. \\
\hline Day 12 & Third debridement (wound closure). \\
\hline Day 45 & Distal tibial corticotomy. \\
\hline Day 52 & $\begin{array}{l}\text { Distal tibial distraction was initiated at a rate of } 1 \mathrm{~mm} / \\
\text { day }(0.25 \mathrm{~mm} 4 \text { times/day). }\end{array}$ \\
\hline Day 322 & The tibia had returned to its original length. \\
\hline Day 1200 & $\begin{array}{l}\text { Union at the docking site and consolidation of bone } \\
\text { regeneration was achieved. The external fixator was } \\
\text { removed. }\end{array}$ \\
\hline
\end{tabular}

Unilateral and annular external fixations may be used for bone transport [25]. A unilateral external fixation was employed in the present case for the following reasons. A unilateral external fixator is less surgically challenging to attach and can control axis better. Furthermore, a unilateral external fixator facilitates early debridement and is associated with increased patient comfort. Additionally, it has a lower impact on the mobility of the knee joint [16].

Despite the long treatment period and the suboptimal outcome obtained, the patient preferred a limb salvage approach to an amputation and is satisfied with the final result. Furthermore, the total cost of limb salvage is lower than that of amputation [26]. The success of the procedure described in the present case report was a result of the cooperation of the patient and his strong desire to preserve the injured limb as well as the followup performed.

As the patient exhibited significantly reduced ankle function, the tibiotalar joint and talocalcaneal joint were attached with a screw when replacing the external fixator. This served to keep the ankle joint in a neutral position and may aid to preserve ankle function and prevent pain and foot drop in later life.

Currently, bone transport is the safest and most effective method for the treatment of massive bone defects. However, this treatment modality requires further optimization as it associated with a number of disadvantages, including a long treatment period, the requirement for repeated surgeries and patient discomfort $[9,16]$. Improvements in medical science and technology may allow the development of novel methods that overcome these limitation and improve patient outcomes.

To the best of the authors' knowledge, the present study described the longest bone defect repair performed using bone transport with single level corticotomy.

\section{Supplementary information}

Supplementary information accompanies this paper at https://doi.org/10. 1186/s12891-019-2927-z.

Additional file 1.

Additional file 2.

Additional file 3.

\section{Abbreviations}

ASAMI: The Association for the study and application of the method of Ilizarov criteria; KSS: Knee society score; LEFS: The lower extremity functional scale; SF-36: Short Form-36; VSD: Vacuum sealing drainage

\section{Acknowledgements}

Not applicable.

\section{Authors' contributions}

HW wrote the manuscript including the literature review. YX had substantial contributions to conception and design. YX and HY had been involved in revising the manuscript critically. All authors have read and approved the final manuscript and greed both to be personally accountable for the author's own contributions and to ensure that questions related to the accuracy or integrity of any part of the work, even ones in which the author was not personally involved, are appropriately investigated, resolved, and the resolution documented in the literature.

\section{Funding}

No funding was received.

Availability of data and materials

All data generated or analyzed during this study are included in this published article.

Ethics approval and consent to participate

Not applicable.

\section{Consent for publication}

We obtained written informed consent from the patient for publication of this case report and any accompanying images and data. A copy of the written consent is available for review by the editor of this journal.

\section{Competing interests}

The authors declare that they have no competing interests.

\section{Author details}

${ }^{1}$ Department of Orthopedic Surgery, The Fourth Affiliated Hospital of Kunming Medical University, 176 Qinnian Road, Wuhua District, Kunming, Yunnan 650021, People's Republic of China. ${ }^{2}$ Department of Orthopedic Surgery, 920th Hospital of Joint Logistics Support Force, 212 Daguan Road, Xi Shan District, Kunming, Yunnan 650031, People's Republic of China.

Received: 19 August 2019 Accepted: 31 October 2019

Published online: 20 November 2019

\section{References}

1. Aktuglu K, Günay H, Alakbarov J. Monofocal bone transport technique for bone defects greater than $5 \mathrm{~cm}$ in tibia: our experience in a case series of 24 patients. Injury. 2016;47:S40-S6.

2. Uzel AP, Lemonne F, Casoli V. Tibial segmental bone defect reconstruction by llizarov type bone transport in an induced membrane. Orthop Traumato Surg Res. 2010;96:194-8.

3. Pipitone PS, Rehman S. Management of Traumatic Bone Loss in the lower extremity. Orthop Clin N Am. 2014;45:469-82.

4. Meselhy MA, Singer MS, Halawa AM, Hosny GA, Adawy AH, Essawy OM. Gradual fibular transfer by ilizarov external fixator in post-traumatic and post-infection large tibial bone defects. Arch Orthop Trauma Surg. 2018 138:653-60. 
5. Megas P, Saridis A, Kouzelis A, Kallivokas A, Mylonas S, Tyllianakis M. The treatment of infected nonunion of the tibia following intramedullary nailing by the llizarov method. Injury. 2010;41:294-9.

6. Konda SR, Gage M, Fisher N, Egol KA. Segmental bone defect treated with the induced membrane technique. J Orthop Trauma. 2017;31:S21-S2.

7. Chaddha M, Gulati D, Singh AP, Singh AP, Maini L. Management of massive posttraumatic bone defects in the lower limb with the llizarov technique. Acta Orthop Belg. 2010;76:811-20.

8. Alkenani NS, Alosfoor MA, Al-Araifi AK, Alnuaim HA. llizarov bone transport after massive tibial trauma: case report. Int I Surg Case Rep. 2016;28:101-6.

9. Green SA. Skeletal defects: a comparison of bone grafting and bone transport for segmental skeletal defects. Clin Orthop Relat Res. 1994;301: $111-7$.

10. Lerner A, Fodor L, Stein H, Soudry M, Peled IJ, Ullmann Y. Extreme bone lengthening using distraction osteogenesis after trauma-a case report. J Orthop Trauma. 2005;19:420-4.

11. Gustilo RB, Mendoza RM, Williams DN. Problems in the management of type III (severe) open fractures: a new classification of type III open fractures. J Trauma. 1984;24:742-6.

12. Song HR, Cho SH, Koo KH, Jeong ST, Park YJ, Koet JH. Tibial bone defects treated by internal bone transport using the llizarov method. Int Orthop. 1998:22:293-7.

13. Insall JN, Dorr LD, Scott RD, Scott WN. Rationale of the knee society clinical rating system. Cslin Orthop Relat Res. 1989;248:13-4.

14. Binkley JM, Stratford PW, Lott SA, Riddle DL. The lower extremity functional scale (LEFS): scale development, measurement properties, and clinical application. North American Orthopaedic rehabilitation research network. Phys Ther. 1999;79:371-83.

15. Ware JE Jr, Sherbourne CD. The MOS 36-item short-form health survey (SF36).I. conceptual framework and item selection. Med Care. 1992;30:473-83.

16. Tong K, Zhong Z, Peng Y, Lin C, Cao S, Yang Y, et al. Masquelet technique versus llizarov bone transport for reconstruction of lower extremity bone defects following posttraumatic osteomyelitis. Injury. 2017;48:1616-22.

17. Rigal S, Merloz P, Le Nen D, Mathevon H, Masquelet AC. Traumatology. Bone transport techniques in posttraumatic bone defects. Orthop Traumatol Surg Res. 2012;98:103-8.

18. Tetsworth K, Paley D, Sen C, Jaffe M, Maar DC, Glatt V, et al. Bone transport versus acute shortening for the management of infected tibial non-unions with bone defects. Injury. 2017;48:2276-84

19. Girard PJ, Kuhn KM, Bailey JR, Lynott JA, Mazurek MT. Bone transport combined with locking bridge plate fixation for the treatment of Tibial segmental defects: a report of 2 cases. J Orthop Trauma. 2013;27:e220-e6.

20. Oh CW, Song HR, Roh JY, Oh JK, Min WK, Kyung HS, et al. Bone transport over an intramedullary nail for reconstruction of long bone defects in tibia. Arch Orthop Trauma Surg. 2008;128:801-8.

21. Wan J, Ling L, Zhang XS, Li ZH. Femoral bone transport by a monolateral external fixator with or without the use of intramedullary nail: a single-department retrospective study. Eur J Orthop Surg Traumatol. 2012;23:457-64.

22. Yang $Z$, Jin L, Tao H, Yang D. Reconstruction of large tibial bone defects following osteosarcoma resection using bone transport distraction: a report of two cases. Oncol Lett. 2016;12:1445-7.

23. Park HW, Yang KH, Lee KS, Joo SY, Kwak YH, Kim HW. Tibial lengthening over an intramedullary nail with use of the llizarov external fixator for idiopathic short stature. J Bone Joint Surg Am. 2008;90:1970-8.

24. Zhang Y, Wang Y, Di J, Peng A. Double-level bone transport for large posttraumatic tibial bone defects: a single Centre experience of sixteen cases. Int Orthop. 2018:42:1157-64.

25. Sala F, Thabet AM, Castelli F, Miller AN, Capitani D, Lovisetti G, et al. Bone transport for Postinfectious segmental Tibial bone defects with a combined llizarov/Taylor spatial frame technique. J Orthop Trauma. 2011;25:162-8.

26. Jauregum JN, Munn J, Maheshwari AV. Limb salvage versus amputation in conventional appendicular osteosarcoma: a systematic review. Indian J Surg Oncol. 2018:9:232-40.

\section{Publisher's Note}

Springer Nature remains neutral with regard to jurisdictional claims in published maps and institutional affiliations.

\section{Ready to submit your research? Choose BMC and benefit from:}

- fast, convenient online submission

- thorough peer review by experienced researchers in your field

- rapid publication on acceptance

- support for research data, including large and complex data types

- gold Open Access which fosters wider collaboration and increased citations

- maximum visibility for your research: over $100 \mathrm{M}$ website views per year

At BMC, research is always in progress.

Learn more biomedcentral.com/submissions 